\title{
(3)
}

\section{Retention of Feminine and Masculine Words by Iranian EFL Learners}

\author{
M. Maghsoudi ${ }^{1}$, M. Mohammad Khani ${ }^{2}$ \\ ${ }^{1}$ Farhangian University, Arak, Iran \\ ${ }^{2}$ Department of English University of Science and Research Branch of Islamic Azad University of Arak \\ Email address: \\ maghsudim@yahoo.com (M. Maghsoudi), mohammadkhani.m82@gmaiul.com (M. Mohammad Khani)
}

\section{To cite this article:}

M. Maghsoudi, M. Mohammad Khani. Retention of Feminine and Masculine Words by Iranian EFL Learners. International Journal of Language and Linguistics. Special Issue: Language Teaching and Learning Key Principles (LTLKP). Vol. 1, No. 4-1, 2013 , pp. 33-39. doi: $10.11648 /$ j.ijll.s.20130101.16

\begin{abstract}
The main concern of the present study was to probe the probable differences between Iranian male and female EFL learners in learning and retention of feminine and masculine words. It was an attempt to investigate whether males and females EFL learners differ significantly in learning and recalling feminine and masculine words. To carry out this study, a total of 32 male and female subjects of Iran language institute in Arak were randomly selected from among two groups of males and females. A vocabulary test and a background questionnaire were administrated to both groups. According to statistical analyses: No significant difference was observed between males and females in masculine and feminine words retention.
\end{abstract}

Keywords: Vocabulary Learning, Vocabulary Retention, Gender, Feminine Word and Masculine Word

\section{Introduction}

In order to live in the world we have to name things. Without name the existence of an object, phenomenon, or even people is too difficult to accept. Accordingly, vocabulary is the building block of any communication (Barani, Mazanandarani, Seyyed Rezaie, 2010 ).

Vocabulary is generally considered as the basic communication tool, and often labeled as the most problematic area by language teachers (Sozler, 2012 ).Even though learners master all grammatical areas in the language, the communication stops when they do not know the necessary word (Sozler, 2012 ).Vocabulary learning is dominant in language acquisition, whether the language is a second or foreign language (Hamzehlou Moghadam , Zainal, Ghaderpoor, 2012 ).

The degree of proficiency in a language is related with the words you know. The more words you know, the better you can express your ideas and communicate with others. Without words people cannot use the language effectively. The importance of learning vocabulary cannot be neglected at all. Many experienced teachers of English as a second or foreign language have realized that knowing a language means knowing its vocabulary as well. We may assert that learning a foreign language is basically a matter of learning a vocabulary of that language. Not being able to find the word you need to express yourself is the most frustrating experience in speaking another language (Dilek and Yuruk, 2012 ).

Language experts have focused on teaching vocabulary to help learners increase their communicative competence and performance. Variety of techniques and activities are recommended to be used in teaching vocabulary. The way vocabulary is selected to be included in teaching materials is a significant factor that affects the process of teaching vocabulary and the learning outcome. Teachers of second or foreign language present new vocabulary item during lessons and at this stage there is no problem, what are waiting for them in the later steps includes difficulties in remembering the words taught in previous lessons and related with this problem there are difficulties in producing sentences and lack of communication (Rahimi, Momeni, Nejati, 2012).

Maghsoudi in 2008 mentioned two types of vocabulary acquisition:

1) Intentional: memorizing straightforwardly term after term with their respective translation from a list.

2) Incidental: Learners acquire vocabulary 
unconsciously when they focus on comprehending meaning from context rather than direct teaching.

There is no doubt that language acquisition is a complex process which involves several factors. Some researches revealed the impact of some factors on the process of vocabulary learning and its retention. As Rahimi, Momeni, and, Nejati stated vocabulary learning strategies may help students learn and remember words in learning a foreign language (2012). The memory strategies lead to positive outcomes in vocabulary learning process and they are more effective in learning new vocabularies and remembering in the long term than traditional learning techniques (Sozler, 2012 ).

Baleghizadeh and Ashoori ,2010) ; Ching-chung and Chun-li (2013) in their study pointed out the superiority of keyword method to simply memorizing word lists.

According to Maghsoudi (2008), the result of immediate and delayed vocabulary tests revealed that subjects using monolingual dictionaries yielded better results in retention of words irrespective of gender and bilinguality of the subjects.

Chun, Choi, and Kim (2012) acknowledged the effectiveness of ER (extensive reading) and PAL (pairedassociate learning) in promoting short-term vocabulary retention and they also stated that ER was considerably more effective than PAL in long-term vocabulary retention.

The obtained results clearly indicate the considerable effect of presenting etymologies on vocabulary retention, particularly when it comes to long-term retention (Baleghizadeh and Yousefpoori Naeim, 2011).

Even though the PLE (Personal Life Experiences) for vocabulary may not have an immediate impact on learners' promotion of reading comprehension, their existing schematic knowledge can significantly influence their performance in vocabulary learning through recall and retention (Marzban and Raeisi ,2012).

The last several decades have seen an explosion of research on the nature and existence

of differences between men and women. One particularly popular question has been the extent to which men and women use language differently (Newman, Groom, Handleman,

Pennebaker, 2008). According to Kaushanskaya, Marian, and Yoo (2011) The presence of gender differences on linguistic tasks suggests that the mechanisms of language acquisition may be somewhat distinct for males and females. They also compared women's and men's performance across the immediate and delayed tests in the field of vocabulary acquisition and its retention and revealed that gender differences are comparable during immediate and delayed retrieval. Also Zare pointed out, females use more language strategies than males during the process of vocabulary learning because they compared to male students are more concerned and anxious about their grades (2010).

\subsection{Hypothesis}

H1: Male and female EFL learners differ significantly in masculine and feminine words retention.

\section{Methodology}

\subsection{Subjects}

The present researchers invited 50 elementary EFL learners both female and male with the age range of 11 to 13 at two classes from Iran Language Institute in Arak (one of the industrial cities of Iran)to participate in present study. The researcher had to exclude 13 students from this study because they were not involved in this range of age and the reminders (N: 37) were categorized through a background questionnaire as follows:

- 20 female EFL learners

-17 male EFL learners

All the participants were at the same level, (elementary) in studying English.

Again the researchers had to exclude 5 students from this study because they were not regularly present during treatment phase and the reminders $(\mathrm{N}: 32,16$ males and 16 females) were undergone this study.

\subsection{Instruments}

The following instruments have been used in this paper:

Background questionnaire: A background questionnaire covering issues as the subjects' full name, age, gender, and linguality status was given to the subject to fill out.

Vocabulary tests: The researchers did her best to ensure that the vocabulary test was an appropriate level of difficulty with words that would be unfamiliar to subjects they were administered in three phases: pre test, post test, and delayed post test.

\subsection{Procedure}

In the process of carrying out the study, the researcher took the following procedures to achieve the objectives of the current study. All the procedures including the development of the background questionnaire and vocabulary test are explained in details below.

Before starting the study, a questionnaire (developed by the researchers) consisted of 40 words was distributed among 40 subjects (20 female EFL learners and 20 male EFL learners). They were asked to determine the feminine and masculine words from their own views. Based on the received feedback $f, 10$ out of 40 words which obtained the minority of concerns as feminine or masculine words were excluded from the questionnaire and the reminders (15 masculine words and 15 feminine words ) were selected as the words used in vocabulary test. Then the researchers developed a 'background questionnaire' in order to elicit some personal information about participants such as: their full name, gender, age, and linguality status.

In order to prevent any possible misunderstanding or 
confusion in the part of the participants and to ensure maximum understanding, the background questionnaire was developed in English along with its translation in Persian. After doing the sampling procedure and choosing subjects randomly 50 students $(25$ female EFL learners and 25 male EFL learners) were initially requested to participate in this study. The conditions for testing were strictly followed as far as possible. The administration of the tests has been completed in three phases:

Phase 1: The background questionnaire and vocabulary test in 25 minutes (the first 5 min was allotted to fill up the background questionnaire and the rest was allotted to vocabulary test as pre test ).

Phase 2: Treatment in 2 weeks,

Phase 3: Post test 1 (immediately after treatment); and

Phase 4: Post test 2(Delayed post test) 2 weeks after immediate post test.

The pre test was a vocabulary test, administered to both groups (20 females and 17 males).It was comprised 30 numbered words (15 female words and 15 male words) randomly arranged and their pictures with a space under each picture, which were randomly arranged after the words. The subjects had to match each pictures with its respective picture by inserting the number of each word in the space beneath them. The time allotted to this phase was 20 minutes.

The next step was to administrate the treatment. It was done by the present researchers. Both of the groups undergone two weeks of treatment (the classes were hold three times a week and the time allotted to treatment was 20 minutes each session), and 15 feminine and 15 masculine words were taught. After two weeks of treatment, the immediate post test took place immediately after treatment. After post test 1(immediate post test) there was no treatment for two weeks and then the above test was repeated(14 days after immediate post-test)without any warning in order to check the retention of the words in delayed post-test. Let it not remain unsaid that in piloting the researchers made sure of reliability and validity of applied test and questionnaire.

\section{Results and Discussion}

To compare the performance of male learners in learning masculine and feminine words, because of existence of several dependant variables the scores of vocabulary learning (pre-test and post-test of learning masculine and feminine words), (GLMRM) was used. The following table is presented in order to report the descriptive statistics such as mean, standard deviation of pre-test scores and post-test ones of learning masculine words and feminine words among by the subjects.

Table 1. Descriptive Statistics (Mean, standard deviation of pre-test scores and post-test scores of learning masculine words and feminine words among the male subjects)

\begin{tabular}{lccc}
\hline & Mean & Std. Deviation & $\mathrm{N}$ \\
\hline PreTest masculine words & 4.69 & 1.815 & 16 \\
PreTest feminine words & 1.50 & .894 & 16 \\
PostTest masculine words & 10.56 & 3.265 & 16 \\
PostTest feminine words & 9.06 & 3.924 & 16 \\
\hline
\end{tabular}

As Table 1 demonstrates, the mean and the standard deviation of masculine words of male subjects' scores in pre-test are respectively 4.69 and 1.815 . and also the mean and the standard deviation of masculine words of male subjects' scores in post-test are respectively 10.56 and 3.26. So we can say that for male subjects the mean score of masculine words in pre-test is very lower than the same mean for mean scores of post-test for masculine words. Also it is worth mentioning that there is a significant difference the mean of pre-test scores of feminine words(1.50) and the mean of its post-test(9.06) for male subjects. The important pre assumption of the variance analysis test with its repeated measures is that the matrices figure of variance and covariance of dependent variables should be spherical. Fortunately, here the dependent variables only have two levels and consequently, spherical feature of these variables are clear. Now by existence of spherical of dependent variables, Table 2 is used in order to consider the significant effects within-subjects.

Table 2. Within-Subjects Effects

\begin{tabular}{|c|c|c|c|c|c|}
\hline \multicolumn{2}{|c|}{ Source } & \multirow{2}{*}{$\frac{\text { Type IV Sum of Squares }}{722.266}$} & \multirow{2}{*}{$\frac{\mathrm{df}}{1}$} & \multirow{2}{*}{$\frac{F}{61.914}$} & \multirow{2}{*}{$\begin{array}{l}\text { Sig. } \\
.000\end{array}$} \\
\hline Time & Sphericity Assumed & & & & \\
\hline Error(Time) & Sphericity Assumed & 174.984 & 15 & & \\
\hline Vocab & Sphericity Assumed & 87.891 & 1 & 61.723 & .000 \\
\hline Error(Vocab) & Sphericity Assumed & 21.359 & 15 & & \\
\hline Time * Vocab & Sphericity Assumed & 11.391 & 1 & 5.363 & .035 \\
\hline Error(Time*Vocab) & Sphericity Assumed & 31.859 & 15 & & \\
\hline
\end{tabular}

Based on the significant values of the last column of Table 2 it can be inferred that all the effects of within- subjects in the level of error of one percent is significant. In other words, the effect of time variables, vocabularies, and the interaction of time and vocabularies on learning of male 
learners with certain of 99 percent is significant. It means that the post-test scores of male learners compared with their pre- test, for each level of error is significantly different. In addition, the significance of interaction between time and vocabularies in the error level of 5\% reveals that the means of pre-test and post-test scores of masculine and feminine vocabulary learning of male learners are significantly different. In order to make the reports more understandable, the graphic diagram is illustrated. The following figure shows the estimated marginal means of pre-test and post-test scores of masculine and feminine vocabulary learning in male subjects.

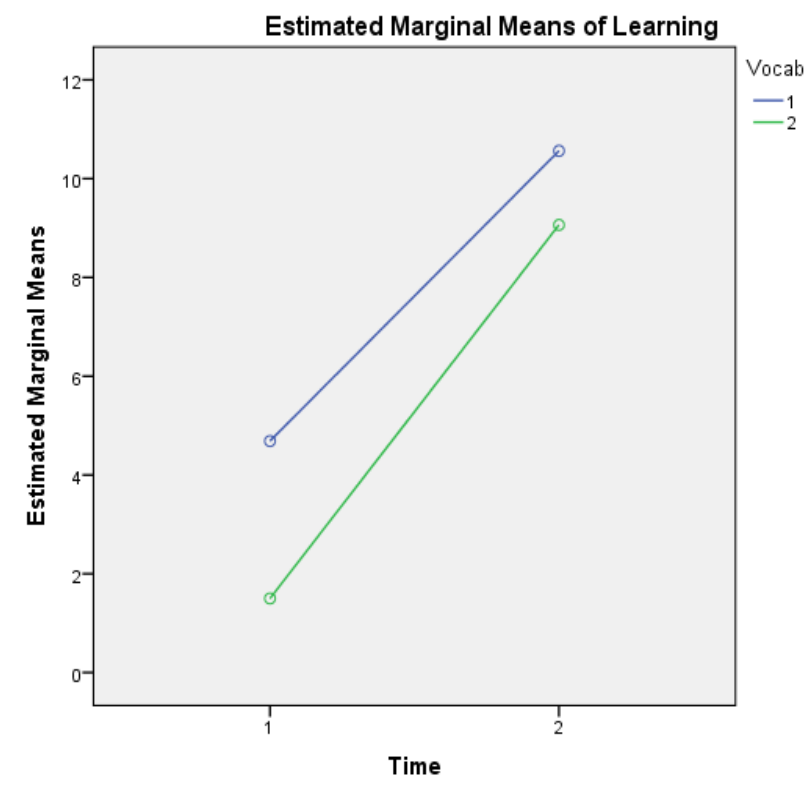

Figure 1. Linear diagram of difference between the learning mean scores of masculine words and feminine words in male subjects.

As it is indicated in Figure 1, the male subjects out performed in learning masculine words compared with feminine words in pre-test. Also this priority has remained in their post-tests. It means the male learner excelled in learning masculine words in post-test too.

Now by obtaining the significance in the learning of masculine and feminine words in male subjects, the difference between learning masculine and feminine words in them (male subjects) will be considered. So for the first step the difference between pre-test scores and post-test scores of feminine and masculine words in male subjects is calculated. So the new variable (masculine words) is made. It is obtained from the difference of the pre-test scores of masculine words in male subjects from their post-test scores in masculine words. Also the other new variable (feminine words) is used like the previous step for feminine words. By doing these the improvement of male subjects in learning masculine and feminine words are obtained. The following table is used to show the descriptive statistics.
Table 3. Paired Samples Statistics

\begin{tabular}{cccccc}
\hline & Mean & N & Std. Deviation & $\begin{array}{c}\text { Std. Error } \\
\text { Mean }\end{array}$ \\
\hline \multirow{2}{*}{ Pair 1 } & Masculine words & 5.88 & 16 & 3.519 & .880 \\
& Feminine words & 7.56 & 16 & 3.898 & .975 \\
\hline
\end{tabular}

By referring to Table 3 it is observed that the means of masculine and feminine words are respectively equal to 5.88 and 7.56. also it is worth noting that standard deviation of masculine and feminine word scores are respectively 3.519 and 3.898 . In order to normality of the masculine and feminine words variables in male subjects the Kolmogorov-smirnov test is used.

Table 4. One-Sample Kolmogorov-Smirnov Test

\begin{tabular}{cccc}
\hline & & $\begin{array}{c}\text { Masculine } \\
\text { words }\end{array}$ & $\begin{array}{c}\text { Feminine } \\
\text { words }\end{array}$ \\
\hline $\mathrm{N}$ & Mean & 5.88 & 16 \\
Normal Parameters ${ }^{\mathrm{a}, \mathrm{b}}$ & Std. Deviation & 3.519 & 3.56 \\
& Absolute & .125 & .245 \\
Most Extreme Differences & Positive & .125 & .245 \\
& Negative & -.115 & -.186 \\
Kolmogorov-Smirnov Z & .498 & .978 \\
Asymp. Sig. (2-tailed) & .965 & .294 \\
\hline
\end{tabular}

a. Test distribution is Normal.

b. Calculated from data.

Based on the reported values from Table 4 and specially the significant level of last row it is clear that because of value of this significant level, their normal assumption is accepted. At first in order to consider the paired value of obtained variables from male subjects Pearson correlation test is used in following Table.

Table 5. Paired Samples Correlations

\begin{tabular}{ccccc}
\hline & $\mathrm{N}$ & Correlation & Sig. \\
\hline Pair 1 & $\begin{array}{c}\text { Masculine and } \\
\text { feminine words }\end{array}$ & 16 & .696 & .003 \\
\hline
\end{tabular}

Concerning the value of significant level $(\mathrm{Sig}=0.003)$ in Table 5, it is clear that the assumption of zero that is the assumption of no correlations between the fore mentioned variables is rejected. It means there is a correlation between the masculine and feminine words variables and so using tstudent test of paired samples is reasonable.

The results of this test which is for considering the difference between means of two paired groups is shown in following table. 
Table 6. Paired Samples Test

\begin{tabular}{|c|c|c|c|c|c|c|c|c|}
\hline \multicolumn{9}{|c|}{ Paired Differences } \\
\hline & & \multirow{2}{*}{ Mean } & \multirow{2}{*}{ Std. Deviation } & \multicolumn{2}{|c|}{$95 \%$ Confidence Interval of the Difference } & \multirow[t]{2}{*}{$\mathrm{t}$} & \multirow[t]{2}{*}{$\mathrm{df}$} & \multirow[t]{2}{*}{ Sig. (2-tailed) } \\
\hline & & & & Lower & Upper & & & \\
\hline Pair 1 & $\begin{array}{l}\text { Masculine words - } \\
\text { Feminine words }\end{array}$ & -1.688 & 2.915 & -3.241 & -.134 & -2.316 & 15 & .035 \\
\hline
\end{tabular}

By referring to significant level in Table $6(\mathrm{Sig}=.035)$ it is clear that for each 0.5 level of error the assumption of zero "equality means of paired groups" is rejected. In other words, the means of learning masculine and feminine words in male subjects are different. Also according to descriptive statistics Table it is obtained that the mean of feminine words learning is higher for male subjects. It means that the $\mathrm{H} 1$ is rejected, as male subjects learn feminine words better than masculine words. The result of this hypothesis is to some extent a support for Zainir et al's study (2012). They attempted to investigate the gender differences in the language use of the Malaysian teen bloggers. The study aimed further at whether the different role of gender effect language using. To carry out this study they have selected subjects from among two groups of boy bloggers and girl bloggers. Statistical analyses revealed that although there are some differences in language use between males and females, in today's world, gender roles are fast changing where stereotyping of men to masculine and women to feminine are no longer prominent. Women are adapting to masculine roles and jobs while men seem to be adopting feminine characteristics in their life. More and more language and gender stereotypes are becoming inapplicable to today's men and women. In general, men and women are known to use language differently, but sometimes they may unintentionally exhibit feminine or masculine speech characteristics respectively when they talk.( Zaini et al, 2012).

Table 7. Descriptive Statistics

\begin{tabular}{|c|c|c|c|c|}
\hline & Gender & Mean & Std. Deviation & $\mathrm{N}$ \\
\hline \multirow{3}{*}{$\begin{array}{l}\text { Delayed post } \\
\text { test for } \\
\text { masculine } \\
\text { words }\end{array}$} & Male & 10.44 & 3.010 & 16 \\
\hline & Female & 10.75 & 3.088 & 16 \\
\hline & Total & 10.59 & 3.004 & 32 \\
\hline \multirow{3}{*}{$\begin{array}{l}\text { Delayed post } \\
\text { test for } \\
\text { feminine } \\
\text { words }\end{array}$} & Male & 8.44 & 4.211 & 16 \\
\hline & Female & 10.31 & 3.478 & 16 \\
\hline & Total & 9.38 & 3.916 & 32 \\
\hline
\end{tabular}

Delayed post-test of masculine and feminine words of males and females

In order to consider the hypothesis of performance of male subjects and female subjects in retention of masculine words and feminine words the analysis of (GLMRM) is used. So in two different groups of questions, two scores of retention of masculine and feminine words among 32 male and female subjects (independent variable gender) is measured. The number of subjects in levels of independent variable gender (male and female) are equal(16). The following table is for reporting the descriptive statistics such as mean, standard deviation of the scores of retention test of masculine and feminine words among the subjects.

As shown in Table 7, the mean and the standard deviation of the scores of retention of masculine words of male subjects are respectively 10.44 and 3.010. Also the mean and the standard deviation of the scores obtained from retention test of feminine words of female subjects are respectively10.31 and 3.478. It is worth noting that these two means are approximately equal. Now, for considering the pre assumption of equality of the observed covariance matrices the dependent variables based on the gender of learners the M.test box Table is used.

Table 8. Box's Test of Equality of Covariance Matrices

\begin{tabular}{c|c}
\hline Box's M & .965 \\
F & .298 \\
df1 & 3 \\
df2 & 162000.000 \\
Sig. & .827 \\
\hline
\end{tabular}

Concerning the low value of Fisher statistic (0.298) and also the high value of the level of significance $(\mathrm{Sig}=0.827)$ from the Table 8 it is obtained that there is no reason to reject the assumption of zero in error level of 0.5 . It means that the observed covariance matrices of dependent variables among the different groups of male and female are equal. The other important pre assumption of GLMRM is that the figure of variance - covariance matrices of dependent variables should be spherical. Fortunately here dependent variables only have two levels so the spherical feature of these dependent variables is clear. Now, by keeping the pre assumption of spherical feature of dependent variables, for considering the significance of within-subjects effects the following Table is used.

Table 9. Tests of Within-Subjects Effects

\begin{tabular}{ccccccc}
\hline \multicolumn{2}{c}{ Source } & $\begin{array}{c}\text { Type IV Sum } \\
\text { of Squares }\end{array}$ & df & F & Sig. \\
\hline Vocab & $\begin{array}{c}\text { Sphericity } \\
\text { Assumed }\end{array}$ & 23.766 & 1 & 6.924 & .013 \\
$\begin{array}{c}\text { Vocab * } \\
\text { Gender }\end{array}$ & $\begin{array}{c}\text { Sphericity } \\
\text { Assumed } \\
\text { Error(Vocab) }\end{array}$ & $\begin{array}{c}\text { Sphericity } \\
\text { Assumed }\end{array}$ & 102.969 & 1 & 2.845 & .102 \\
\hline
\end{tabular}

Measure: Learning 
Based on the values of significant level (Sig) in the last column of Table 9, it is inferred that the first withinsubjects effect in the error level of 0.5 is significant. In other words, the effect of vocabularies variable on the retention of masculine and feminine words is significant. It means that the mean scores of retention test of masculine and feminine words (delayed post-test) is significantly different. But the second within-subjects effect in the error level of 0.05 is not significant. It means that the nonsignificant interaction between time and gender shows that the mean scores of retention tests of masculine and feminine words in female learners and male learners has no significant difference. In other words, the mean scores of masculine and feminine word retention in male and female learners are close to each other and according to Descriptive statistics Table (Table 7) it is inferred that the male learners and the female ones are at the same level of retention of masculine and feminine words. In order to make the reported issues more understandable the graphic diagram is presented. The following figure illustrates the estimated marginal means of learning estimated from the scores of masculine and feminine words retention in male subjects and female subjects.

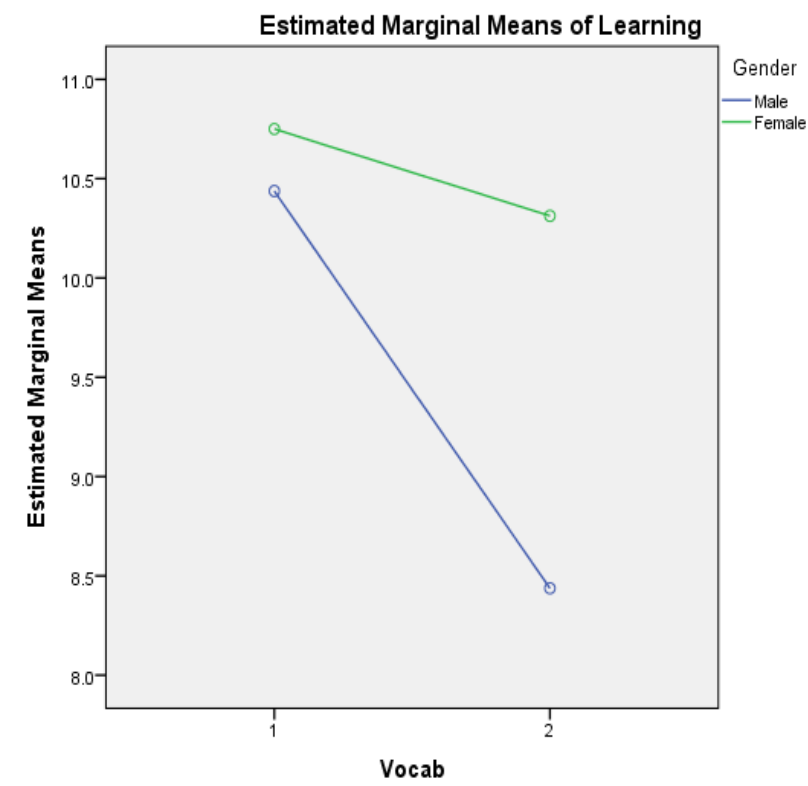

Figure 2. Linear diagram of considering the difference between the mean scores of masculine and feminine words retention test in male subjects and female subjects.

As shown in figure 2, the mean score of masculine words retention test in male learners is approximately equal to the mean score of feminine words retention test in female learners. In other words there is no difference between these two means. Even it is worth noting that the male learners did weaker in feminine word retention, while the females did better in masculine word retention. In order to consider the pre assumption of (GLMRM) the following Table which contains the values of Levene's test is used for equality of error variances.
Table 10. Levene's Test of Equality of Error Variances ${ }^{a}$

\begin{tabular}{ccccc}
\hline & F & df1 & df2 & Sig. \\
\hline Delayed Test males & .162 & 1 & 30 & .690 \\
Delayed Test females & .434 & 1 & 30 & .515 \\
\hline
\end{tabular}

Tests the null hypothesis that the error variance of the dependent variable is equal across groups.

a. Design: Intercept + Gender

Within Subjects Design: Vocabulary

By referring to Table 10, the reported values of $\mathrm{F}$ for male learners and female learners respectively (0.162 and $0.434)$ and the value of significance level for male learners and female learners respectively Sig (0.690 and 0.515), it is clear that there is no reason to reject the assumption of existed zero(equality of error variances). So, the equality of error variances of scores of masculine and feminine word retention of male and female learners are assumed equal.

The test of between subjects effects is shown in following Table in order to consider the significance and non-significance of whole model and also the separate effect of independent variable (gender) on dependent variable (retention of feminine and masculine words).

Table 11. Tests of Between-Subjects Effects

\begin{tabular}{cccccc}
\hline Source & $\begin{array}{c}\text { Type IV Sum } \\
\text { of Squares }\end{array}$ & df & Mean Square & F & Sig. \\
\hline Intercept & 6380.016 & 1 & 6380.016 & 307.054 & .000 \\
Gender & 19.141 & 1 & 19.141 & .921 & .345 \\
Error & 623.344 & 30 & 20.778 & & \\
\hline
\end{tabular}

Measure: Learning

Transformed Variable: Average

Regarding the reported value in Table 11, it is clear that the level of significance of gender variable (second row) is higher than 0.05 and consequently it has no significant effect on dependent variable of scores of masculine and feminine word retention. In other words the hypothesis 2 is rejected as there is no significant difference between the mean score of masculine and feminine word retention in male and female learners. The result of this hypothesis can be to some extant a support for what Rahimi et al.(2012) has declared. According to Rahimi et al.(2012), Vocabulary learning strategies may help students learn and remember words in learning a foreign language. Further, Zare's (2010) study revealed that females use more language strategies than males because they are more concerned about their grades. Zare (2010) also declared that females' greater use of language learning strategies does not necessarily mean that girls are more successful than boys in the process of language learning. 


\section{Conclusion}

To carry out this study, a pre-experimental design was employed. A total of 32 male and female subjects at two classes of Iran institute in Arak, Iran were randomly selected from among two groups of male and female EFL learners. A vocabulary test and background questionnaire were administrated to both groups. Statistical analyses including pre-test, post-test, delayed post-test, SPSS, and descriptive analyses revealed that there were no significant differences in the performance of the two learner groups, that is male and female learners. The results and the findings of the statistical analyses may be summarized as follows:

The result of data analysis indicated that there is no significant difference in masculine and feminine word learning for male learners. It is often believed that males tend to learn masculine words and females tend to learn feminine words. This belief rests on an implicit assumption that males are more interested in male topics and females are more interested in female topics. This hypothesis to some extents supports Zaini et al's finding (2012) in which they revealed that more and more language and gender stereotypes are becoming inapplicable to today's men and women. Men and women are known to use language differently, but sometimes they may unintentionally exhibit feminine or masculine speech characteristics respectively when they talk.

It was also indicated that no significant relationship was observed between gender and word retention. This hypothesis is to some extent in line with findings of Zare who concluded (2010) although females use more language learning strategies than male ones, there is no significant difference between males' and females' success in the process of language learning.

\section{References}

[1] Alami,M. ,Sabbah,M., \& Iranmanesh,M.(2013). MaleFemale discourse difference in terms of lexical density. Research Journal of Applied Sciences, Engineering and Technology, 5(23), 5365-5369.

[2] Alipour, M., Gorjian, B., \&Zafari, I.(2012). The effects of songs on EFL learners' vocabulary recall and retention: The case of gender. Advances in Digital Multi Media(ADMM)1(3),2166-2916.

[3] Baleghizadeh,S. \& Ashoori, A.(2010). The effect of keyword and list word methods on immediate vocabulary retention of EFL learners. Pakistan Journal of Social Sciences,30(2),251-261.

[4] Baleghizadeh,S. \& Yousefpoori Naeim,M.(2011). Promoting vocabulary retention through etymology presentation. Journal of Theory and Practice in Education, 7(1), 111-123.

[5] Barani, Qh., Mazandarani,O., \& Seyyed Hassani,S.(2010). The effect of application of picture into picture audio- visual aids on vocabulary learning of young Iranian EFL learners. Science Direct, 2(2010), 5362 -5369.

[6] Ching-Chung, G. \& Chan Li,Ch. (2013). Learning styles and keyword association variations on vocabulary retention. British Journal of Education, Society and Behaviourial Science, 4(1), 19-33.

[7] Chun,E. Choi,S. \& Kim,J.(2012). The effect of Extensive reading and Paired associate learning on long-term vocabulary retention: An event-related potential study. $S c i$ Verse Science Direct, 521(2012) 125-129.

[8] Demir, Y.(2013) The role of in-class vocabulary strategies in vocabulary retention of Turkish EFL learners. Nentary Education Online,12(4), 1173-1187. Retrieved December 11,2013 from http://ilkogretim-online.org.tr

[9] Dilek,Y. \& Yuruk, N.(2012). Using semantic mapping technique in vocabulary teaching at pre-intermediate level. Sci Science Direct, 70(2013), 1531-1544.

[10] Hamzehlou Moghadam, S., Zainal, Z.,\& Ghaderpour,M.(2012). A review on important role of vocabulary knowledge in reading comprehension performance. Sci Science Direct, 66(2012), 555-563.

[11] Kaushanskaya, M., Marian, V., \& Yoo, J.(2011). Gender differences in adult word learning. Science Direct, 137(2011), 24-35.

[12] Maghsoudi,M. (2008) Type of Task and Type of Dictionary in Incidental Vocabulary Acquisition.RetrievedDecember6,2013fromhttp://bibiloteca virtualut.Suagm.edu/Glossa2/journal/jun2008

[13] Marzban, A. \& Raeisi,M.(2012). The impact of personal life experience on the recall and retention of vocabulary in reading comprehension of upper- intermediate EFL Iranian learners. Sci Science Direct, 70(2013).

[14] Rahimi, M. Momeni,Gh., \& Nejati,R.(2011). The impact of lexically-based language teaching on students achievement in learning English as a foreign language. SciVerse Science Direct 31(2012), 31-36.

[15] Shakouri, N. \&Saligheh,M.(2012). Revisiting age and gender influence in second language acquisition. Advances and Gender Influence in Second Language Acquisition (AEL), 1(2012),56-60.

[16] Sozler,S.(2012). The effect of memory strategy training on vocabulary development of Austrian secondary school students. Sci Verse Science Direct, Procedia-Social and Behavioral Sciences, 46(2012), 1348-1352.

[17] Zahedi,Y. \& Abdi, M.(2012). The impact of imagery strategy on EFL learners'vocabulary learning. SciVerse Science Direct, 69(2012), 2264-2272.

[18] Zaini, A. , Abidin,H., Darus, S, Ismail, K.(2012) Gender differences in the language use of Malaysian teen bloggers. GEMA online Journal of Language Studies.2(1). Retrieved December 8, 2013 from http://www.ukmmy/ppbl/Gema/

[19] Zare,P. (2010). An investigation into language learning strategy use and gender among Iranian under graduate language learners. World Applied Sciences Journal,11(10), $1238-1247$ 